\title{
Lovastatin induces apoptosis of ovarian cancer cells and synergizes with doxorubicin: potential therapeutic relevance
}

\author{
Anna Martirosyan ${ }^{\dagger 1}$, James W Clendening ${ }^{+1,2}$, Carolyn A Goard 1,2 and Linda Z Penn*1,2
}

\begin{abstract}
Background: Ovarian carcinoma is a rarely curable disease, for which new treatment options are required. As agents that block HMG-CoA reductase and the mevalonate pathway, the statin family of drugs are used in the treatment of hypercholesterolemia and have been shown to trigger apoptosis in a tumor-specific manner. Recent clinical trials show that the addition of statins to traditional chemotherapeutic strategies can increase efficacy of targeting statin-sensitive tumors. Our goal was to assess statin-induced apoptosis of ovarian cancer cells, either alone or in combination with chemotherapeutics, and then determine these mechanisms of action.

Methods: The effect of lovastatin on ovarian cancer cell lines was evaluated alone and in combination with cisplatin and doxorubicin using several assays (MTT, TUNEL, fixed PI, PARP cleavage) and synergy determined by evaluating the combination index. The mechanisms of action were evaluated using functional, molecular, and pharmacologic approaches.

Results: We demonstrate that lovastatin induces apoptosis of ovarian cancer cells in a p53-independent manner and synergizes with doxorubicin, a chemotherapeutic agent used to treat recurrent cases of ovarian cancer. Lovastatin drives ovarian tumor cell death by two mechanisms: first, by blocking HMG-CoA reductase activity, and second, by sensitizing multi-drug resistant cells to doxorubicin by a novel mevalonate-independent mechanism. This inhibition of drug transport, likely through inhibition of P-glycoprotein, potentiates both DNA damage and tumor cell apoptosis.

Conclusions: The results of this research provide pre-clinical data to warrant further evaluation of statins as potential anti-cancer agents to treat ovarian carcinoma. Many statins are inexpensive, off-patent generic drugs that are immediately available for use as anti-cancer agents. We provide evidence that lovastatin triggers apoptosis of ovarian cancer cells as a single agent by a mevalonate-dependent mechanism. Moreover, we also show lovastatin synergizes with doxorubicin, an agent administered for recurrent disease. This synergy occurs by a novel mevalonateindependent mechanism that antagonizes drug resistance, likely by inhibiting P-glycoprotein. These data raise important issues that may impact how statins can best be included in chemotherapy regimens.
\end{abstract}

\section{Background}

As a malignancy with particularly poor prognosis, novel therapeutic options are urgently required for the treatment of ovarian cancer[1,2] In 2009, approximately 25,000 women will be diagnosed in North America and most will die of their disease, making it the fifth leading cause of cancer mortality in women[3] The majority of

\footnotetext{
*Correspondence: Ipenn@uhnres.utoronto.ca

1 Ontario Cancer Institute/Princess Margaret Hospital, Campbell Family Institute for Cancer Research, Toronto, ON, Canada +Contributed equally
}

ovarian cancer cases present as advanced stage III or IV disease and treatment usually involves surgical cytoreduction, followed by adjuvant platinum/taxane chemotherapy, with about $70-80 \%$ response rates. While patients typically undergo a period of remission of 1-2 years, more than half eventually relapse. Some patients with recurrent disease become refractory to platinum treatment. They are generally next treated with regimens of gemcitabine, topotecan, and/or liposomal doxorubicin, but with very limited success[4,5] The reduced rate of response in these patients is typically due to the develop- 
ment of drug resistance[6] Taken together, to directly increase the quality and longevity of life, new and immediate therapeutic approaches are urgently required to combat ovarian cancer.

We and others have shown that the statin family of drugs exhibit antiproliferative activity against cancer cells without causing collateral damage to normal cells[7]. Statins inhibit the rate-limiting enzyme of the mevalonate (MVA) pathway, HMG-CoA reductase (HMGCR), and have been used for decades as safe and effective agents in the control of hypercholesterolemia[7,8] In addition to cholesterol, the MVA pathway gives rise to a number of crucial biochemical end-products, including ubiquinone, dolichol, isopentenyladenine, and isoprenoid precursors. Statins can trigger tumor cells to undergo a classic caspase-dependent, apoptotic response that is reversible by exogenous addition of MVA or the isoprenoid precursors, geranylgeranyl pyrophosphate (GGPP) and farnesyl pyrophosphate (FPP)[7]. Thus, the statin family of drugs are immediately available for use as part of the arsenal of molecular targeted therapeutics to combat cancer.

Like most anti-cancer agents, statins demonstrate robust efficacy on some but not all tumor-types, emphasizing the importance of matching the agent with the sensitive, responsive cancer. Statins have been extensively shown to trigger apoptosis of cell lines derived from haematological malignancies, including acute myelogenous leukemia and multiple myeloma[7,9]. This preclinical data has been recently translated to Phase I/II clinical trials that have shown promising results when statins have been used in combination with standard chemotherapy[10,11] Similarly, median survival was doubled with the addition of statins to 5-fluorouracil in advanced hepatocellular carcinomas[12] As was recently reviewed, solid tumor derived cell lines that have recently been shown to be statin sensitive include breast, colorectal, lung, prostate, and pancreatic, [13]. however, preclinical work focusing on ovarian cancer is required to determine whether statins have the potential to be used to combat this tumor type as well. Very recently, preliminary reports have indicated that ovarian carcinoma is sensitive to statin-induced apoptosis, providing a unique alternative to treating this deadly disease[14,15].

To advance these findings, we demonstrate that lovastatin induces apoptosis of ovarian cancer cells in a p53independent manner and synergizes with doxorubicin, a chemotherapeutic agent used to treat recurrent ovarian cancer. Lovastatin triggers ovarian tumor cells to undergo apoptosis by two mechanisms: first, by blocking HMGCR activity; and second, by increasing the level of doxorubicin within drug-resistant cells. Together, these data support further pre-clinical and clinical evaluations of statins as a new strategy to combat ovarian cancer and overcome drug resistance.

\section{Methods \\ Cells}

Cells were grown as a monolayer in RPMI 1640 medium with $10 \%$ fetal bovine serum in a humidified incubator at $37^{\circ} \mathrm{C}$ in $5 \% \mathrm{CO}_{2}$. Ectopic expression of the ecotropic receptor was conducted as described[16]. and subsequent gene transfer was achieved by infection with retrovirus produced using the Phoenix ecotropic packaging system as previously described[17] A2780 cells were generated to ectopically express either a p53DD construct or the empty YFP vector control by flow sorting for stably expressing cells[17] Cells were also generated and selected to ectopically express $\mathrm{Bcl}-2$ and its corresponding empty vector control.

\section{MTT assays}

The MTT assays were conducted as previously described[18]. except 3750 cells/well of a 96-well plate were plated and after 24 hours, cells were exposed to lovastatin (5 to $100 \mu \mathrm{M}$; activated as previously described[19]) for 48 hours followed by MTT tetrazolium substrate for 2 hours.

\section{Immunoblotting}

Cells were seeded in $100 \mathrm{~mm}$ dishes for 24 hours. Treatments of $20 \mu \mathrm{M}$ lovastatin or vehicle control were completed for 24 or 48 hours before cells were harvested for PARP (Cell Signaling Technology), Rap1 (Santa Cruz Biotechnology), p53 (Santa Cruz Biotechnology), actin (Sigma-Aldrich), and tubulin (Calbiochem) immunoblotting as described $[9,17]$ Lysates from cells exposed to $8 \mathrm{GY}$ of radiation for 8 hours were immunoblotted for p21 (Santa Cruz Biotechnology) and tubulin. Lysates from A2780 pBP, A2780 Bcl-2, A2780ADR GFP and A2780ADR Bcl-2 were immunoblotted for Bcl-2 and tubulin.

\section{Fixed PI}

Cells were seeded in $100 \mathrm{~mm}$ dishes for 24 hours and exposed to indicated lovastatin concentrations or vehicle control for indicated times (24, 48, or 72 hours), washed in PBS, fixed in $70 \%$ ethanol, stained with $50 \mu \mathrm{g} / \mathrm{mL}$ PI (Sigma-Aldrich) and analyzed by a FACScalibur flow cytometer (BD Bioscience). Ten thousand events were scored and analysis was performed using Cell Quest software (BD Bioscience) to assess the dying, pre-G1 population.

\section{Synergy experiments}

Cells were plated for MTT assays and treated for 24 hours with concentration ranges of lovastatin and either doxorubicin or cisplatin that are centered on each drug's $\mathrm{MTT}_{50}(\mathrm{~A} 2780 \mathrm{ADR}-20,14$, and $42 \mu \mathrm{M}$, respectively; A2780 - 10, 4, $50 \mu \mathrm{M}$, respectively; A2780CIS - 30, 5, 112 $\mu \mathrm{M}$, respectively). CEMVBL cells were similarly plated 
and treated with lovastatin and doxorubicin, also centered on each drug's $\mathrm{MTT}_{50}$ (42 and $68 \mu \mathrm{M}$, respectively). Drug treatments were performed individually or in fixed ratio combinations (at $4 \times, 2 \times, 1 \times, 1 / 2 \times, 1 / 4 \times, 1 / 8 \times$ $\mathrm{MTT}_{50}$ values) as described previously[20]. Combination index (CI) plots were generated using CalcuSyn software (Ver 2; Biosoft) based on algorithms developed by Chou and Talalay[21] to determine whether the drugs synergize $(\mathrm{CI}<1)$.

\section{Measurement of P-gp expression}

As previously described, [22] $1 \times 10^{6}$ cells were harvested, washed in $1 \mathrm{~mL}$ buffer (1xPBS, 0.5\%BSA), resuspended in $1 \mathrm{~mL}$ staining buffer (1xPBS, 0.5\%BSA, $0.1 \% \mathrm{NaN} 3)$ with or without $20 \mu \mathrm{L}$ of FITC-labelled anti-human P-gp (BD Pharmigen), and incubated on ice for 40 minutes in the dark. Cells were washed with staining buffer, resuspended in $1 \mathrm{~mL}$ buffer, and fluorescence in the FL1 channel was detected by flow cytometry. 10000 events were captured for analysis with Cell Quest software.

\section{Measurement of intracellular doxorubicin}

Intracellular doxorubicin was measured as described previously[23]. with some alterations. Briefly, for accumulation experiments, $2 \times 10^{5} \mathrm{~A} 2780 \mathrm{ADR}$ cells were seeded in 6-well plates for 24 hours and treated. Alternatively, $5 \times$ $10^{5}$ CEMVBL cells were seeded and treated in 6-well plates. A2780ADR cells were exposed to $7 \mu \mathrm{M}$ doxorubicin (half $\mathrm{MTT}_{50}$ ) alone or in combination with 5, 10 or 20 $\mu \mathrm{M}$ lovastatin for 3 hours. An additional sample was treated with doxorubicin, $10 \mu \mathrm{M}$ lovastatin, and $100 \mu \mathrm{M}$ MVA as well. CEMVBL cells were exposed to $34 \mu \mathrm{M}$ doxorubicin (half $\mathrm{MTT}_{50}$ ) alone or in combination with 2.63, $5.25,10.5$ or $21 \mu \mathrm{M}$ lovastatin for 3 hours. An additional sample was treated with doxorubicin, $21 \mu \mathrm{M}$ lovastatin, and $100 \mu \mathrm{M}$ MVA as well. For retention experiments, A2780ADR cells were incubated with a combination of 7 $\mu \mathrm{M}$ doxorubicin and $10 \mu \mathrm{M}$ lovastatin as above and were further incubated for two hours in doxorubicin-free media with or without $10 \mu \mathrm{M}$ lovastatin. For both accumulation and retention experiments, after treatment, cells were washed twice in cold phosphate buffered saline (PBS), resuspended in $1 \mathrm{~mL}$ of cold PBS, and filtered for single cells on ice. Intracellular doxorubicin fluorescence was measured by detecting the natural fluorescence of doxorubicin with flow cytometry (FL2 channel); 10,000 events were scored.

\section{Comet assay}

A2780ADR cells were seeded in $100 \mathrm{~mm}$ plates for 24 hours and exposed to either a control, $10 \mu \mathrm{M}$ lovastatin, 7 $\mu \mathrm{M}$ doxorubicin, or both $10 \mu \mathrm{M}$ lovastatin and $7 \mu \mathrm{M}$ doxorubicin together for 24 hours. Comet assays were performed as described previously[24] Briefly, comets were visualized by fluorescence microscopy (Axioskop microscope, Zeiss) and images were analyzed using Komet 5.5 software (Kinetic Imaging). DNA damage was quantified from the analysis of 75 comets per treatment/experiment using the olive tail moment [Tail moment $=(\% \mathrm{DNA}) \times$ (distance traveled)].

\section{TUNEL assay}

TUNEL and PI dual-staining was carried out as per manufacturer's instructions (APO-BRDU kit; Phoenix Flow systems Inc.). Briefly, 2 million cells were seeded in 100 $\mathrm{mm}$ plates for 24 hours and treated with the indicated drugs for 24 hours to determine both the proportion of TUNEL-positive cells and the cell cycle phase from which apoptotic cells arose.

\section{Results}

Human ovarian carcinoma cells are sensitive to lovastatin-

\section{induced apoptosis}

To evaluate the sensitivity of human ovarian cancer cells to the anti-proliferative activity of statins, a panel of ten ovarian cancer cell lines was exposed to increasing concentrations of lovastatin for 48 hours. Lovastatin was the statin used in this study because it is readily available as a generic drug and is lipophilic, a feature of statins that have shown efficacy in recent breast cancer studies[25,26] MTT assays showed that lovastatin exposure triggered a substantial decrease in activity in all cell lines with $\mathrm{MTT}_{50}$ values that ranged from approximately 2 to $40 \mu \mathrm{M}$ (Figure 1A).

To further define the antiproliferative effect of lovastatin, we next used two independent methods to evaluate whether lovastatin triggered apoptosis in the cell line panel. We first assessed the population of pre-G1 cells by fixed PI flow cytometry in response to $20 \mu \mathrm{M}$ lovastatin for 48 hours. This fixed dose was used in all cell lines to be able to compare relative sensitivity. In all ten cell lines tested, an increase in the pre-G1 population was measured (Figure 1B, histograms, and data not shown). As an independent assay for apoptosis we assessed whether the cleavage of poly ADP-ribose polymerase (PARP) was detectable in cells treated with either lovastatin or vehicle control for 48 hours. Cleaved PARP was observed in all cell lines, except DOV13 (Figure 1B, inset western blots, and data not shown). Thus, ovarian cancer cells undergo apoptosis in response to lovastatin exposure.

Treating cells with $20 \mu \mathrm{M}$ lovastatin for 48 hours elicited a robust apoptotic response from which a potent MVA-dependent rescue would be required. Cells were co-treated with lovastatin and either $100 \mu \mathrm{M}$ MVA, 10 $\mu \mathrm{M}$ GGPP, or $10 \mu \mathrm{M}$ FPP to determine if lovastatininduced apoptosis in ovarian cancer cells is MVA-dependent. MVA reversed the effect of lovastatin and both GGPP and FPP were also able to partially rescue cells 


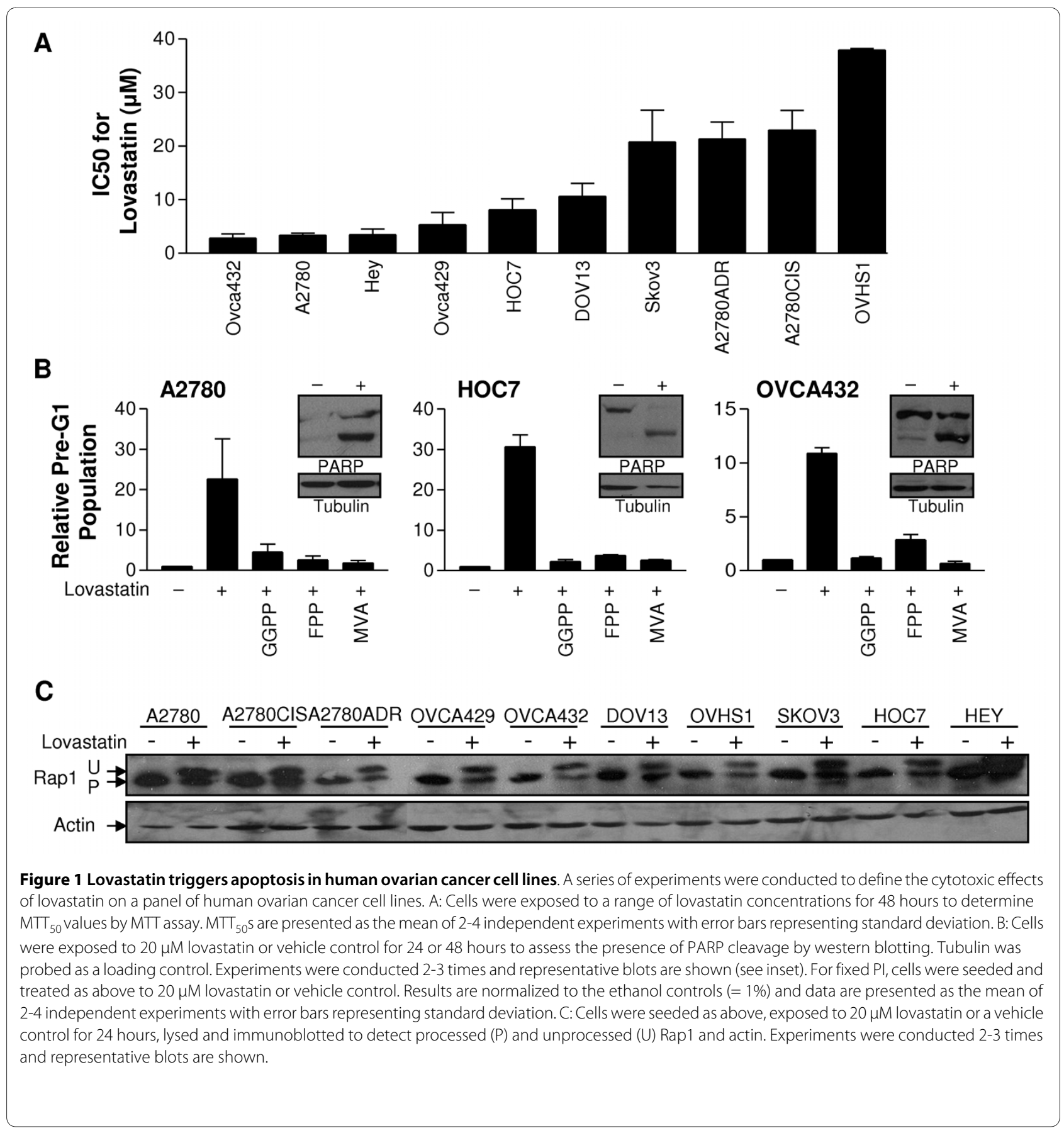

(Figure 1B, and data not shown). The mechanism of lovastatin-induced apoptosis in ovarian cancer cells is therefore dependent upon HMGCR inhibition.

To ensure that the MVA pathway block was due to lovastatin we evaluated the prenylation status of Rap1, a protein that is known to be exclusively geranylgeranylated (Figure 1C). Immunoblot analysis showed accumulation of the unprocessed form of Rap1 in all cell lines exposed to lovastatin for 24 hours, indicating that drug uptake was universally achieved.
Lovastatin triggers apoptosis of human ovarian carcinoma cells in a time and dose dependent manner

Novel treatment options for women diagnosed with ovarian cancer are sorely needed. Our data suggests that statins have potential to be used as chemotherapeutics for these patients but it is important to determine whether they are effective at therapeutically achievable (low micromolar) concentrations. As a representative sensitive ovarian cancer cell line, A2780 cells were exposed to increasing concentrations of lovastatin $(1,5,10$, and 20 
$\mu \mathrm{M})$ for 24,48 , and 72 hours before being harvested for fixed PI analysis and the population of pre-G1 cells measured (Figure 2). Consistent with previous studies in AML, [11,27-30] the results clearly demonstrate that lovastatin-induced apoptosis of these cells is both doseand time-dependent, and that the $20 \mu \mathrm{M}, 24$ hour lovastatin treatment commonly used in the laboratory is not significantly different $(\mathrm{p}=0.49)$ from clinically achievable doses of lovastatin for 72 hours.

\section{Lovastatin-induced apoptosis of human ovarian carcinoma cells is p53-independent}

To identify molecular features of cancers that predict sensitivity, we evaluated the role of the tumor suppressor p53 in lovastatin-induced apoptosis of ovarian cancer cells. Taking a molecular approach, a dominant negative p53 truncation, p53DD, was ectopically expressed in A2780 cells (Figure 3A). These cells are known to harbor endogenous wildtype p53 [31]. The activity of p53 in these cells was evaluated by exposing them to $8 \mathrm{GY}$ of gamma-irradiation measuring p53-dependent induction of the cyclin-dependent kinase inhibitor, p21. As expected, p21 was induced after irradiation of parental and empty vector-expressing cells, but this induction was substantially decreased in A2780-p53DD cells (Figure 3B).

As a positive control for the inhibition of lovastatininduced apoptosis, A2780 cells ectopically expressing Bcl-2 or the corresponding empty vector were also analyzed (Figure 3C). Fixed PI was used to measure the preG1 population of cells treated with $20 \mu \mathrm{M}$ lovastatin for 24 hours (Figure 3D). Empty vector controls and cells expressing p53DD underwent a similar degree of apoptosis while ectopic expression of $\mathrm{Bcl}-2$ significantly decreased the amount of lovastatin-induced apoptosis by
$50 \%$, demonstrating the p53-independence of lovastatininduced apoptosis in human ovarian cancer cells.

\section{Lovastatin synergizes with doxorubicin in P-gp expressing cells}

As statins will likely be used in cancer treatment as part of drug cocktails, we next evaluated whether the addition of lovastatin to agents presently used in chemotherapy regimes of ovarian cancer would increase efficacy. Cisplatin and doxorubicin were selected as representative agents used in the treatment of primary and relapsed drug-resistant ovarian cancer. To model primary onset disease A2780 cells were treated in combination with cisplatin and lovastatin. To model relapsed disease A2780ADR cells, a multi-drug resistant cell line derived from parental A2780 cells, were treated with lovastatin in combination with either cisplatin or doxorubicin. Synergy experiments were adapted from the methods described by Chou and Talaly [21] to determine the antiproliferative effect of drug combinations with lovastatin. In A2780ADR cells, lovastatin and cisplatin were additive $(\mathrm{C}=1)$ when combined at higher concentrations (Figure 4A, white bars). By contrast, lovastatin significantly synergized with doxorubicin in drug-resistant A2780ADR cells $(\mathrm{CI}<1$; Figure 4A, black bars).

A commonly proposed mechanism of multi-drug resistance (MDR) in recurrent ovarian cancer is elevated drug efflux, which is often due to increased activity of the ATP-binding cassette $(\mathrm{ABC})$ transporter $A B C B 1$ (previously named $M D R 1$ ) gene that encodes P-glycoprotein (P-gp)[4] A2780ADR cells, previously developed by culturing parental A2780 cells in the presence of doxorubicin, have gained resistance to the drug by overexpressing P-gp, [22] which we confirmed by flow cytometry with a fluorescence-tagged antibody to P-gp (Figure 4C, left).

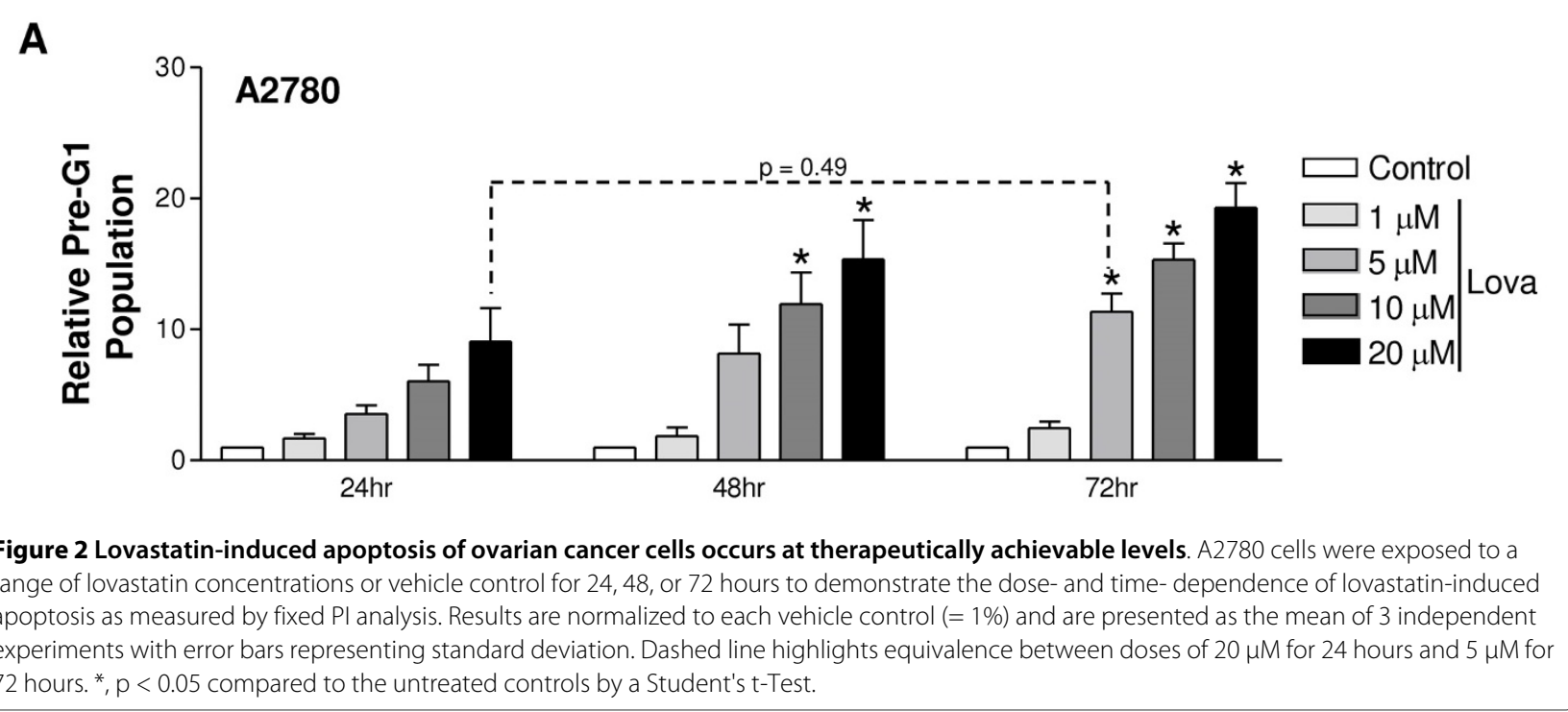




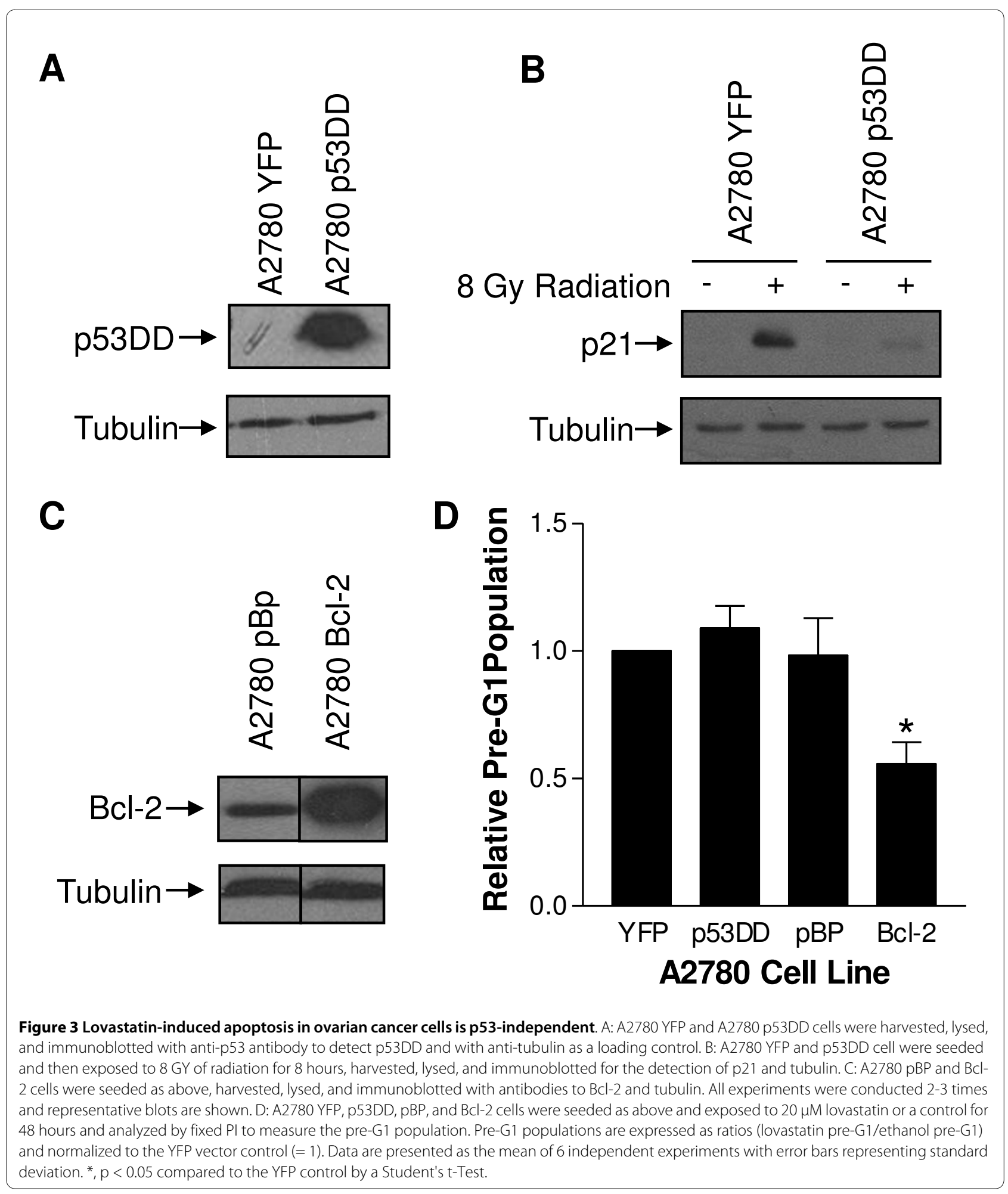

Additionally, the $\mathrm{MTT}_{50}$ for doxorubicin determined by MTT assay in A2780ADR cells ( $4.9 \mu \mathrm{M}$ at 48 hours; 3.1 to $7.795 \%$ CI) was approximately 100 times higher than in A2780 cells $(0.04 \mu \mathrm{M}$ at 48 hours; 0.03 to $0.0695 \% \mathrm{CI})$. We hypothesized that P-gp mediated efflux of doxorubi- cin, a known substrate of P-gp, was being blocked by lovastatin via an unknown mechanism. To verify that synergy between lovastatin and doxorubicin was not simply an artifact of the A2780ADR cell system, we employed an alternative paired parental and MDR model derived 
A

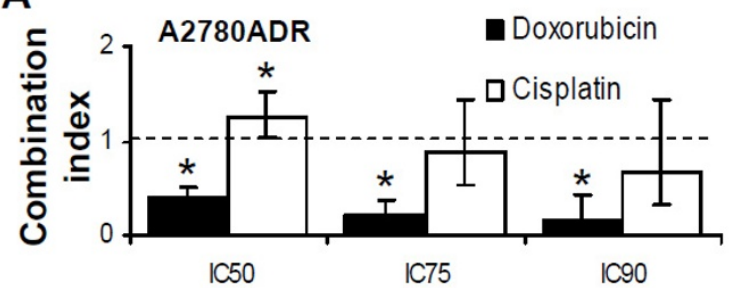

B

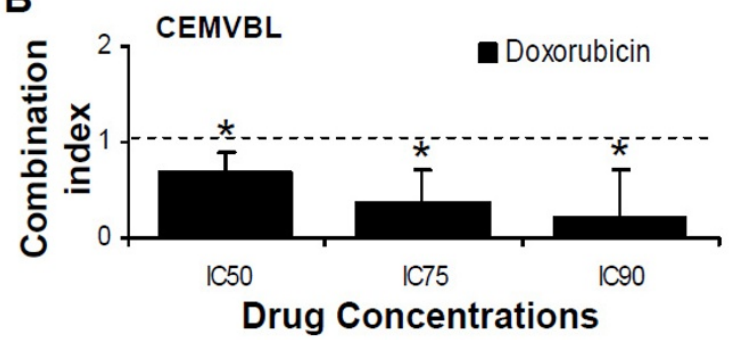

C

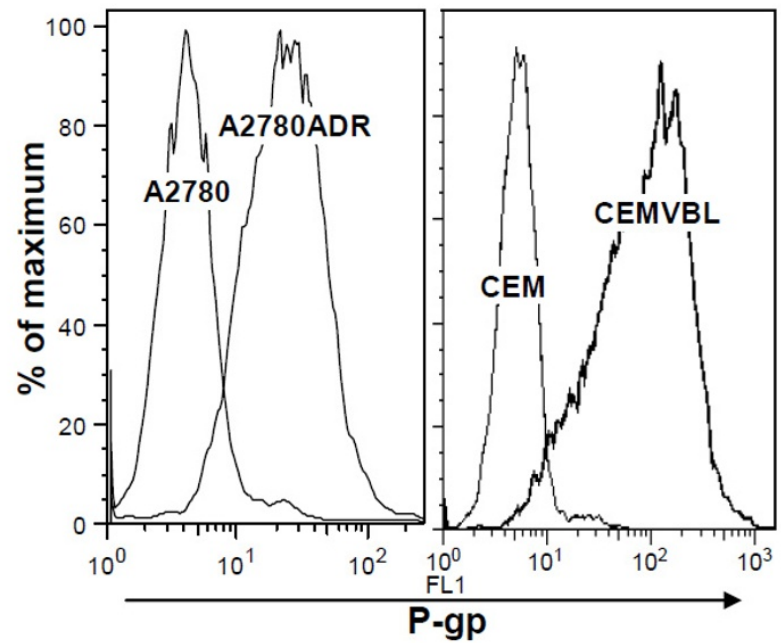

Figure 4 Lovastatin synergizes with doxorubicin in P-gp expressing ovarian cancer cells. A2780ADR (A) and CEMVBL (B) cells were plated for MTT assays and treated for 24 hours with concentration ranges of lovastatin and either doxorubicin or cisplatin. Combination index (Cl) plots were generated using CalcuSyn software to determine whether the drugs synergize $(\mathrm{Cl}<1)$. Data is presented as the mean of 5-10 independently determined $\mathrm{Cl}$ values with error bars representing standard deviation. ${ }^{*}, \mathrm{p}<0.05$ compared to additivity $(\mathrm{Cl}=1)$ by a Single Sample t-Test. C: Substantially higher P-gp expression was detected by flow cytometry in A2780ADR and CEMVBL cells compared to A2780 and CEM cells, respectively, using a fluorescence-tagged anti-P-gp antibody. The experiment was conducted 3 times; a representative histogram is shown.

from acute lymphoblastic leukemia, CEM and CEMVBL cells, respectively. We also confirmed that the CEMVBL cells both overexpress P-gp on their cell surface and have a significantly higher $\mathrm{MTT}_{50}$ for doxorubicin when compared to the parental CEM cells (Figure 4C, right, and data not shown). Interestingly, lovastatin synergized significantly with doxorubicin in CEMVBL cells (Figure 4B) using the same experimental design as above. We also determined that lovastatin did not synergize with cisplatin in either parental A2780 cells (Additional file 1: Supplemental Figure S1A) or the drug-resistant A2780CIS cells (Additional file 1: Supplemental Figure S1B), both of which had little to no P-gp expression compared to A2780ADR cells (Additional file 1: Supplemental Figure S1C). Furthermore, lovastatin and doxorubicin were borderline synergistic or additive in A2780 and A2780CIS (Additional file 1: Supplemental Figure S1) cells treated in a similar manner.

\section{Lovastatin increases doxorubicin retention in P-gp expressing cells}

To elucidate the molecular mechanisms underlying this synergy we formulated a working model in which lovastatin blocks P-gp, thereby inhibiting its ability to drive the efflux of doxorubicin from MDR cells. As the fluorescence of doxorubicin can be directly measured by flow cytometry, we evaluated the amount of doxorubicin within A2780ADR and CEMVBL cells exposed to a sublethal dose of doxorubicin alone or in combination with increasing concentrations of lovastatin. Notably, A2780ADR (Figure 5A) and CEMVBL (Figure 5B) cells exposed to a combination of lovastatin and doxorubicin contained more intracellular doxorubicin than cells treated with doxorubicin alone. This process was dosedependent, as increasing concentrations of lovastatin led to an increase in the accumulation of intracellular doxorubicin, but also observed at low physiologically relevant concentrations of both lovastatin (Figure 5A; 5B) and doxorubicin (data not shown).

Lovastatin also appears to prevent the active efflux of doxorubicin (Figure 5C). In this experiment, cells were treated with lovastatin and doxorubicin together to "load" the cells with doxorubicin. To determine differential degrees of doxorubicin retention, cells were further incubated for 2 hours in doxorubicin-free media with or without lovastatin. Remarkably, incubation with lovastatin resulted in more intracellular doxorubicin remaining after 2 hours. Partial loss of doxorubicin observed in cells that were incubated with lovastatin is likely due to passive diffusion or efflux mediated by alternative mechanisms because this same pattern was observed in parental A2780 cells, which do not overexpress P-gp, treated in the same manner (data not shown). These data suggest that lovastatin may inhibit P-gp from actively pumping doxorubicin out of the cell. Surprisingly, lovastatin-induced accumulation of doxorubicin was not reversed by coincubation with MVA (Figure 5A; B), suggesting that a mechanism independent of HMGCR inhibition is at 


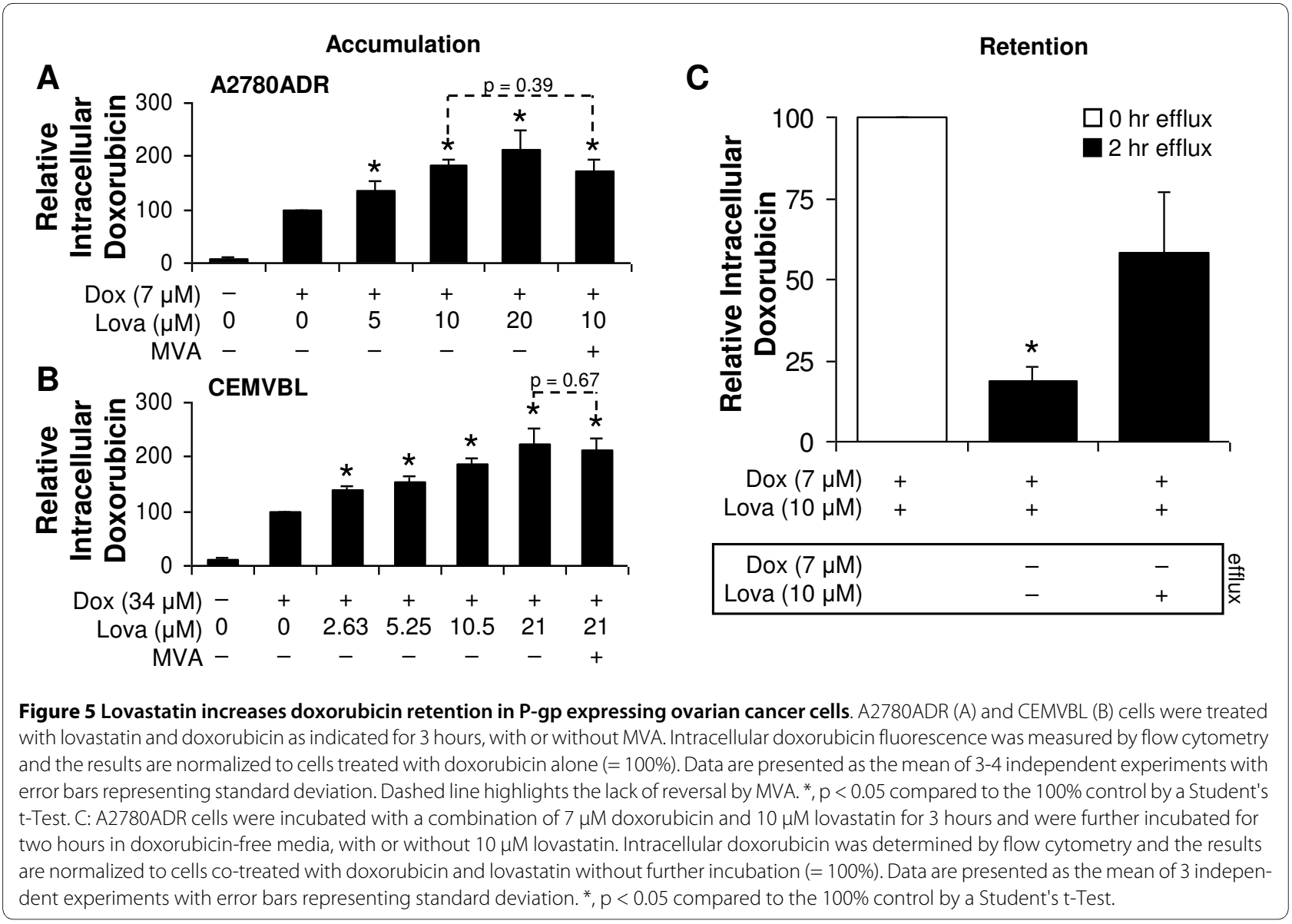

work. This data provides support for the combined use of lovastatin and chemotherapeutics that are substrates of P-gp to increase efficacy of tumor cell death.

\section{Combining lovastatin and doxorubicin potentiates DNA damage and apoptosis in P-gp expressing cells}

To further explore the mechanisms synergy between lovastatin and doxorubicin, we next measured DNA damage, commonly induced by doxorubicin, by comet assay. Drug concentrations used in this set of experiments were relatively sub-lethal, half-MTT ${ }_{50}$ values to minimize the effect of each drug on its own. Although these doses are higher than physiologically achievable levels, they remain experimentally tractable. While doxorubicin exposure alone resulted in a slight, significant increase in DNA damage compared to either control- or lovastatin-treated cells, combined treatment with both lovastatin and doxorubicin together resulted in a statistically significant 3fold increase in DNA damage over doxorubicin alone (Figure 6A).

We next determined whether lovastatin could also potentiate doxorubicin-induced apoptosis. For these experiments we used dual-staining of TUNEL and fixed PI to measure the degree of apoptosis and determine if cells undergo apoptosis preferentially from any particular phase of the cell cycle. A2780ADR cells were treated as before and analyzed by flow cytometry. Similar to the comet assays, doxorubicin alone induced a small increase in apoptosis compared to either the control- or lovastatin-treated cells (Figure 6B). Cells treated with lovastatin alone, however, showed no evidence of either DNA damage or apoptosis. This is expected due to the low, sublethal dose used. Conversely, cells exposed to the combination of lovastatin and doxorubicin underwent a statistically significant 10 -fold increase in apoptosis when compared to doxorubicin alone. While over-expression of Bcl-2 did not inhibit the combined activity of lovastatin and doxorubicin (Additional file 2: Supplemental Figure S2), apoptotic cells were detected from all phases of the cell cycle (Figure 6C). Therefore, doxorubicin and lovastatin combine synergistically to induce high levels of both DNA damage and apoptosis in human ovarian cancer cells.

\section{Discussion}

Our work provides important evidence to support further pre-clinical and clinical evaluation of the statin family of drugs as anticancer agents against ovarian cancer. 


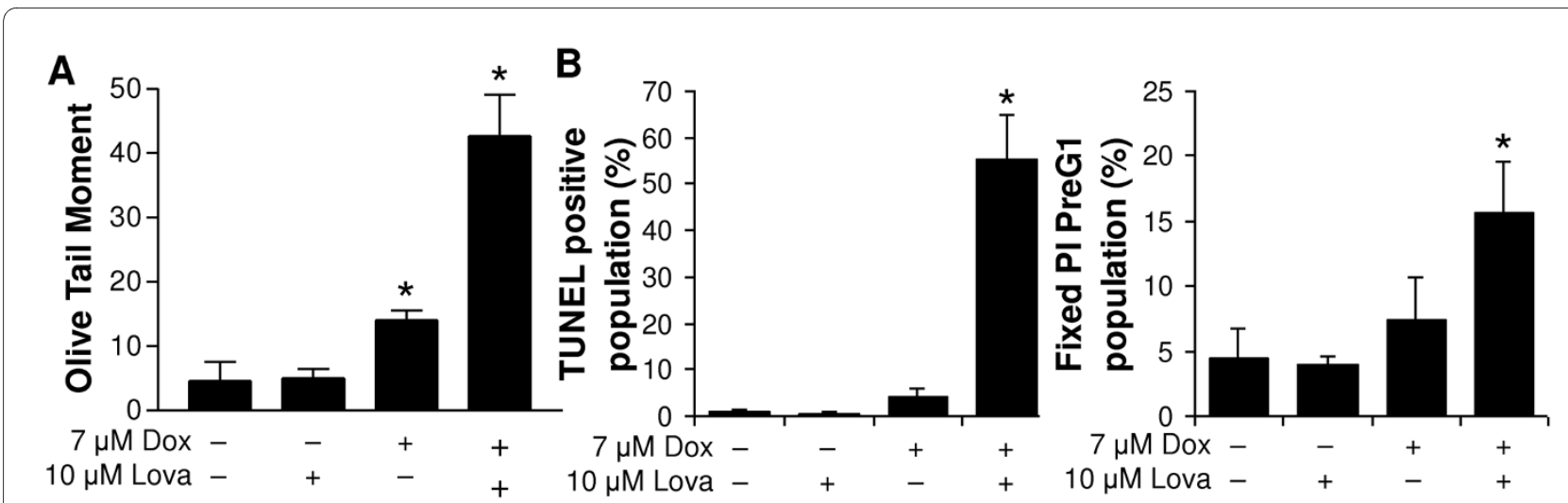

C

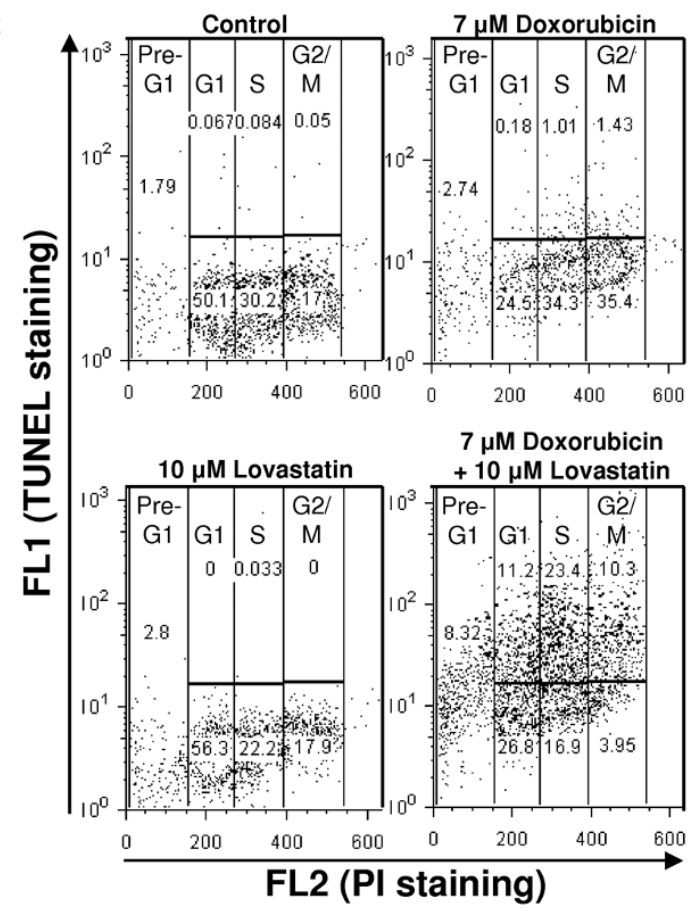

D

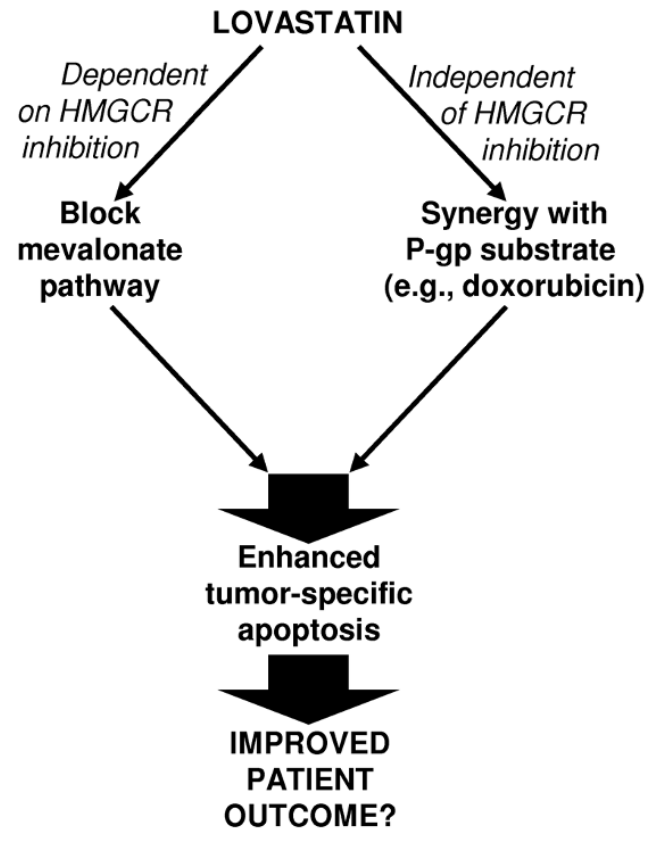

Figure 6 Lovastatin potentiates DNA damage and apoptosis induced by doxorubicin. A2780ADR cells were exposed to either a control, $10 \mu \mathrm{M}$ lovastatin, $7 \mu \mathrm{M}$ doxorubicin, or both $10 \mu \mathrm{M}$ lovastatin and $7 \mu \mathrm{M}$ doxorubicin together. A: Comet assays were performed and the olive tail moment determined for 75 cells of each condition. Data are presented as the mean of 4 independent experiments with error bars representing standard deviation. ${ }^{*}, \mathrm{p}<0.05$ compared to the untreated control by a Student's t-Test. TUNEL and PI dual-staining was carried out to determine the proportion of TUNEL-positive cells and if apoptotic cells originated predominantly in any particular phase of the cell cycle. B: Data are presented as the mean of 3 independent experiments measuring either TUNEL positivity (left) or PreG1 population (right) with error bars representing standard deviation. ${ }^{*}, \mathrm{p}$ $<0.05$ compared to the untreated control by a Student's t-Test. C: Representative dot plots comparing the degree of TUNEL staining to DNA content. D: Schematic model illustrating two independent mechanisms of statin activity and the manner in which they can be combined to maximize clinical efficacy.

We show that a panel of ovarian cancer derived cell lines is sensitive to lovastatin-induced apoptosis, consistent with recent reports[14,15]. Mechanistically this apoptotic pathway is functionally blocked by exogenous MVA or the isoprenoid precursors GGPP and FPP. Moreover, we show that statin killing occurs irrespective of the mutational status of the tumor suppressor p53. Our results using a dominant negative p53 clearly indicate that lovastatin-induced apoptosis is substantially p53-independent and this is also supported by the observation that p53null SKOV3 cells are able to undergo lovastatin-induced apoptosis. These observations are particularly important for ovarian cancer in which p53 mutation rates have been estimated between 23 and $79 \%[32]$. We also show that lovastatin can synergize with doxorubicin and potentiate apoptosis. Synergy is achieved by lovastatin blocking drug efflux through a MVA-independent mechanism that enables the intracellular retention and genotoxic action of 
doxorubicin. To the best of our knowledge, these latter features of statin-induced apoptosis have not yet been reported for ovarian cancer. Exploiting the unique ability of statins to drive apoptosis by the mevalonate-dependent mechanism alone warrants further evaluation of these agents in the treatment of ovarian cancer (Figure $6 \mathrm{D}$, left side). In addition, using statins, like lovastatin, to synergize with chemotherapeutics that are P-gp substrates (Figure 6D, right side) may be a feature of lovastatin action that further maximizes ovarian cancer cell death and improves patient survival.

It is interesting to note that while several reports have shown that P-gp expressing cells were more sensitive statin-induced apoptosis, [33-36] our results show the opposite trend (Figure 1A). Indeed, the $\mathrm{MTT}_{50}$ results for lovastatin in A2780ADR and A2780CIS cells are roughly 5 -fold higher than in the parental A2780 cells. The reason for this difference is unknown, but it is possible that the drug resistant cells have exploited additional mechanisms of resistance, such as increasing the expression of antiapoptotic proteins.

As agents approved for use in humans, the MVAdependent antiproliferative activity of statins has prompted several Phase I clinical trials of statins on a wide variety of late-stage cancers, and although statins were well tolerated, only limited responses were evident. More recently statins have been evaluated on cohorts of patients harboring a tumor-type that has been shown to be sensitive to statin-induced apoptosis in tissue culture studies. In these focused, tumor-specific, hypothesisdriven trials, statins have demonstrated some efficacy as a single agent $[29,30,37]$ but more wide-reaching effects were evident when statins were combined with chemotherapeutics $[10,11,38,39]$. Thus, our data identifying ovarian carcinoma as a statin-sensitive tumor type strongly supports the evaluation of statins in strategies to combat this disease.

A recent, retrospective epidemiological study showed that statin use in patients diagnosed with epithelial ovarian cancer is associated with improved survival[40]. Although only a relatively small number of patients met the criteria for the study, multivariable analysis identified statin use as an independent positive prognostic factor after controlling for age, stage, grade, and suboptimal cytoreduction, providing clinical support for the use statin-based combinations in cancer treatment. Similar recent analyses of breast cancer also provided additional insights. For example, it appears that lipophilic statin use after breast cancer diagnosis has been associated with decreased risk of recurrence[25,26]. Overall, these recent studies provide supporting rationale for the use of statins as anticancer agents and suggest that lipophilic statins (lovastatin, simvastatin, atorvastatin, fluvastatin, and pitavastatin) may be more effective, perhaps because they are better able to penetrate solid tumors compared to hydrophilic statins. From a pharmacological perspective, the lipophilic statins that demonstrate higher plasma concentrations with longer retention times in the circulation include atorvastatin and fluvastatin. This suggests these lipophilic agents may best target the tumor and show higher anti-cancer efficacy in vivo, consistent with a previous study comparing lipophilic and hydrophilic statins in ovarian cancer[15].

Recent evidence suggests that there may be a connection between drug resistance and regulation of the MVA pathway. In MDR AML cells, HMGCR mRNA levels were not significantly elevated upon statin exposure in cells that showed preferential sensitivity to lovastatin[36]. More recently, it was suggested that high levels of HMGCR mRNA correlates with sensitivity to statininduced apoptosis[15]. It will be interesting in the future to determine how HMGCR expression impacts statin sensitivity and whether it can be exploited as a biomarker.

Mechanistically, it is clear that statins target HMG-CoA reductase and similarly trigger tumor cells to undergo apoptosis[7]. (Figure 6D, left side), however, several practical questions remain unresolved regarding statins as potential P-gp inhibitors (Figure 6D, right side). This new role of statins would be particularly important to consider in the management of ovarian cancer as survival and disease recurrence after taxane/carboplatin treatment has recently been associated with specific P-gp polymorphisms[41]. Several classes of specific P-gp inhibitors have been developed but have unfortunately shown general cytotoxicity in clinical trials[42]. This is thought to be due to targeting P-gp not only on tumor cells, but also on several normal vital organs that constitutively express P-gp. It would be easy to assume that statins blocking P-gp will similarly cause general cytotoxicity, however, it is not known whether statins and classic P-gp inhibitors are mechanistically or functionally similar. Lovastatin has been reported to inhibit P-gp in a limited number of biochemical studies with two very distinct caveats: none have used human cells overexpressing drug-selected human P-gp and the concentrations of drug used have been well beyond the physiologically achievable range [43-46]. Moreover, the results of these studies have been in conflict when using either the acid or lactone form of the statin[45,46]. Importantly, we conducted our work with physiologically attainable concentrations of both doxorubicin and lovastatin in human cell systems selected to overexpress human P-gp.

It is also worth noting that $\mathrm{Bcl}-2$ was unable to inhibit cell death induced by the combination of lovastatin and doxorubicin (Additional file 2: Supplemental Figure S2). While the reasons for this result are unclear, it is possible that the cells have become drug-resistant through means other than the MDR machinery, such as upregulation of 
one or more anti-apoptotic proteins, and thereby rendered forced expression of Bcl-2 incapable of rescuing cells further. Further study will be required to better understand the interplay of all mechanisms of drug resistance.

Statins ultimately need to advance to clinical trials where their inhibition of drug efflux can be monitored on both tumor and normal cells. Interestingly, other groups have reported that lovastatin protects normal cells from doxorubicin-induced cytotoxicity [47-49] which, when combined with our data, suggests that statins may affect P-gp differently in normal cells compared to tumor cells. It is entirely possible that lovastatin functionally blocks Pgp in a manner that is distinct from classic P-gp inhibition. Evidence that statins can be successfully combined with various $\mathrm{P}$-gp substrates is also established from their safe and effective combination in the polypharmacy of cardiac patients with hypercholesterolemia[50]. Taken together, our results suggest the ability of statins to trigger apoptosis of ovarian cancer cells may be exploited in the treatment of this disease, and that the potential P-gp inhibitory properties of certain statins, like lovastatin, warrant further investigation. It is also of interest to note that at $\mathrm{MTT}_{50}$ concentrations, but not higher, lovastatin had a slightly antagonistic relationship with cisplatin, a non-P-gp substrate (Figure 4A, Additional file 1: Supplemental Figure S1). This observation suggests that it could potentially be deleterious to combine lovastatin with cisplatin in the treatment of some patients. Furthermore, lovastatin and doxorubicin were also able to synergize in A2780 parental and A2780CIS cells. While this suggests that elements other than P-gp are involved in the interaction between these two drugs, the degree of synergy observed in A2780ADR cells is higher, indicating that inhibition of P-gp is likely an important mechanism of how lovastatin synergizes with doxorubicin. These results require further investigation to truly understand the manner by which lovastatin functionally interacts with other chemotherapeutics.

Determining which statin will maximally target different tumors, including ovarian, under different conditions will also be vital to advancing patient care. In the 14 completed and 20 or more ongoing clinical trials evaluating statins in the prevention or treatment of cancer, [1012,30,37-39,51-57] the rationale for choosing a particular statin is not presented and appears random. Indeed, the ideal choice of statin as an anti-cancer agent remains unclear, however, evidence suggests lipophilic agents with pharmacologic properties that favor access to solid tumors is of high priority. Further work is required to better understand the activity of these statins as potential inhibitors of P-gp and to determine if this inhibition is specific to tumor cells in vivo.

\section{Conclusions}

Overall, our results identify ovarian cancer cells as sensitive to statin-induced apoptosis and strongly suggest that statins can play a role in the treatment of ovarian carcinoma. As approved agents, statins can make immediate impact either as additions to traditional inductive therapy, as maintenance therapy to secure lasting remissions, or as salvage treatment for terminal, refractory disease. Our results may impact ongoing clinical trials using statins as anti-cancer agents and will be important to consider in the design of future clinical trials targeting various tumor types, including ovarian cancer.

\section{Additional material}

Additional file 1 Supplemental Figure S1. Supplementary data that shows lovastatin did not synergize with cisplatin in either parental A2780 cells or drug-resistant A2780CIS cells and that lovastatin and doxorubicin were borderline synergistic or additive in A2780 and A2780CIS cells.

Additional file 2 Supplemental Figure S2. Supplementary data that shows $\mathrm{BCl}-2$ was unable to inhibit cell death induced by the combination of lovastatin and doxorubicin

\section{Competing interests}

The authors declare that they have no competing interests.

\section{Authors' contributions}

AM and JWC carried out experiments, participated in the design of the study, and contributed to drafting the manuscript. CAG carried out experiments. LZP conceived of the study, participated in its design and coordination, and helped to draft the manuscript. All authors read and approved the final manuscript.

\section{Acknowledgements}

We would like to express our profound appreciation to Dr. Theodore J. Brown for his enthusiasm in the initiation of this project. Sincere thanks to members of the Penn lab for helpful discussions and critical review of the manuscript as well as to the following for providing necessary reagents: Dr. Theodore J. Brown (The Samuel Lunenfeld Research Institute, Toronto, ON, Canada; Skov3, Ovca429, Hey, and HOC-7 cells), Dr. Richard B. Pearson (Peter MacCallum Cancer Centre, Melbourne, Australia; DOV13, Ovca432, and OVHS-1 cells), Dr. Jeremy Squire (University of Toronto, Toronto, ON, Canada; A2780, A2780ADR, and A2780CIS cells), Dr. Aaron Schimmer (University of Toronto, Toronto, ON, Canada; CEM and CEMVBL cells), Dr. David Andrews (McMaster University, Hamilton, ON, Canada; Bcl-2 antibody), and Apoptex Corporation (lovastatin). This study was conducted with the support of the Ontario Institute for Cancer Research Network through funding provided by the Province of Ontario (LZP), a fellowship from the Leukemia and Lymphoma Society of Canada (AM), Excellence In Radiation Research for the 21st Century Strategic Training Initiative In Health Research award from the Canadian Institutes for Health Research (JWC), and Ontario Graduate Scholarships (JWC and CAG).

\section{Author Details}

1Ontario Cancer Institute/Princess Margaret Hospital, Campbell Family Institute for Cancer Research, Toronto, ON, Canada and ${ }^{2}$ Department of Medical Biophysics, University of Toronto, Toronto, ON, Canada

Received: 29 April 2009 Accepted: 18 March 2010 Published: 18 March 2010

\section{References}

1. Markman M: Antineoplastic agents in the management of ovarian cancer: current status and emerging therapeutic strategies. Trends Pharmacol Sci 2008, 29(10):515-519.

2. Markman M: Pharmaceutical management of ovarian cancer: current status. Drugs 2008, 68(6):771-789. 
3. Jemal A, Siegel R, Ward E, Hao Y, Xu J, Murray T, Thun MJ: Cancer statistics, 2008. CA Cancer J Clin 2008, 58(2):71-96.

4. Agarwal R, Kaye SB: Ovarian cancer: strategies for overcoming resistance to chemotherapy. Nat Rev Cancer 2003, 3(7):502-516.

5. Ozols RF, Bookman MA, Connolly DC, Daly MB, Godwin AK, Schilder RJ, Xu $X$, Hamilton TC: Focus on epithelial ovarian cancer. Cancer Cell 2004, 5(1):19-24.

6. Hille S, Rein DT, Riffelmann M, Neumann R, Sartorius J, Pfutzner A, Kurbacher CM, Schondorf T, Breidenbach M: Anticancer drugs induce mdr1 gene expression in recurrent ovarian cancer. Anticancer Drugs 2006, 17(9):1041-1044.

7. Wong WW, Dimitroulakos J, Minden MD, Penn LZ: HMG-CoA reductase inhibitors and the malignant cell: the statin family of drugs as triggers of tumor-specific apoptosis. Leukemia 2002, 16(4):508-519.

8. Goldstein JL, Brown MS: Regulation of the mevalonate pathway. Nature 1990, 343(6257):425-430.

9. Wong WW, Clendening JW, Martirosyan A, Boutros PC, Bros C, Khosravi F, Jurisica I, Stewart AK, Bergsagel PL, Penn LZ: Determinants of sensitivity to lovastatin-induced apoptosis in multiple myeloma. Mol Cancer Ther 2007, 6(6):1886-1897.

10. Schmidmaier R, Baumann P, Bumeder I, Meinhardt G, Straka C, Emmerich $B$ : First clinical experience with simvastatin to overcome drug resistance in refractory multiple myeloma. Eur J Haematol 2007, 79(3):240-243.

11. Kornblau SM, Banker DE, Stirewalt D, Shen D, Lemker E, Verstovsek S, Estrov Z, Faderl S, Cortes J, Beran M, et al:: Blockade of adaptive defensive changes in cholesterol uptake and synthesis in AML by the addition of pravastatin to idarubicin + high-dose Ara-C: a phase 1 study. Blood 2007, 109(7):2999-3006.

12. Kawata S, Yamasaki E, Nagase T, Inui Y, Ito N, Matsuda Y, Inada M, Tamura S, Noda S, Imai Y, et al:: Effect of pravastatin on survival in patients with advanced hepatocellular carcinoma. A randomized controlled trial. $\mathrm{Br} J$ Cancer 2001, 84(7):886-891.

13. Sassano A, Platanias LC: Statins in tumor suppression. Cancer Lett 2008, 260(1-2):11-19.

14. Liu H, Liang SL, Kumar S, Weyman CM, Liu W, Zhou A: Statins induce apoptosis in ovarian cancer cells through activation of JNK and enhancement of Bim expression. Cancer Chemother Pharmacol 2008.

15. Kato S, Smalley S, Sadarangani A, Chen-Lin K, Oliva B, Branes J, Carvajal J, Gejman R, Owen Gl, Cuello M: Lipophilic but not hydrophilic statins selectively induce cell death in gynecological cancers expressing high levels of HMGCoA reductase. $J$ Cell Mol Med 2009.

16. Wu J, Wong WW, Khosravi F, Minden MD, Penn LZ: Blocking the Raf/MEK/ ERK pathway sensitizes acute myelogenous leukemia cells to lovastatin-induced apoptosis. Cancer Res 2004, 64(18):6461-6468.

17. Kim SS, Shago M, Kaustov L, Boutros PC, Clendening JW, Sheng Y, Trentin GA, Barsyte-Lovejoy D, Mao DY, Kay R, et al.: CUL7 is a novel antiapoptotic oncogene. Cancer Res 2007, 67(20):9616-9622.

18. Dimitroulakos J, Nohynek D, Backway KL, Hedley DW, Yeger H, Freedman $M H$, Minden MD, Penn LZ: Increased sensitivity of acute myeloid leukemias to lovastatin-induced apoptosis: A potential therapeutic approach. Blood 1999, 93(4):1308-1318.

19. Keyomarsi K, Sandoval L, Band V, Pardee AB: Synchronization of tumor and normal cells from $\mathrm{G} 1$ to multiple cell cycles by lovastatin. Cancer Res 1991, 51(13):3602-3609.

20. Raje N, Kumar S, Hideshima T, Ishitsuka K, Chauhan D, Mitsiades C, Podar K, Le Gouill S, Richardson P, Munshi NC, et al: Combination of the mTOR inhibitor rapamycin and CC-5013 has synergistic activity in multiple myeloma. Blood 2004, 104(13):4188-4193.

21. Chou TC, Talalay P: Quantitative analysis of dose-effect relationships: the combined effects of multiple drugs or enzyme inhibitors. $A d v$ Enzyme Reg 1984, 22:27-55.

22. Jekerle V, Kassack MU, Reilly RM, Wiese M, Piquette-Miller M: Functional comparison of single- and double-stranded mdr1 antisense oligodeoxynucleotides in human ovarian cancer cell lines. J Pharm Pharm Sci 2005, 8(3):516-527.

23. Garcia-Escarp M, Martinez-Munoz V, Sales-Pardo I, Barquinero J, Domingo $J$ J, Marin P, Petriz J: Flow cytometry-based approach to ABCG2 function suggests that the transporter differentially handles the influx and efflux of drugs. Cytometry A 2004, 62(2):129-138

24. Martirosyan A, Leonard S, Shi X, Griffith B, Gannett P, Strobl J: Actions of a histone deacetylase inhibitor NSC3852 (5-nitroso-8-quinolinol) link reactive oxygen species to cell differentiation and apoptosis in MCF-7 human mammary tumor cells. J Pharmacol Exp Ther 2006, 317(2):546-552.

25. Kwan ML, Habel LA, Flick ED, Quesenberry CP, Caan B: Post-diagnosis statin use and breast cancer recurrence in a prospective cohort study of early stage breast cancer survivors. Breast Cancer Res Treat 2008, 109(3):573-579.

26. Campbell MJ, Esserman LJ, Zhou Y, Shoemaker M, Lobo M, Borman E, Baehner F, Kumar AS, Adduci K, Marx C, et al.: Breast cancer growth prevention by statins. Cancer Res 2006, 66(17):8707-8714.

27. Dimitroulakos J, Thai S, Wasfy GH, Hedley DW, Minden MD, Penn LZ: Lovastatin induces a pronounced differentiation response in acute myeloid leukemias. Leuk Lymphoma 2000, 40(1-2):167-178.

28. Dimitroulakos J, Ye LY, Benzaquen M, Moore MJ, Kamel-Reid S, Freedman $\mathrm{MH}$, Yeger $\mathrm{H}$, Penn LZ: Differential sensitivity of various pediatric cancers and squamous cell carcinomas to lovastatin-induced apoptosis: therapeutic implications. Clin Cancer Res 2001, 7(1):158-167.

29. Minden MD, Dimitroulakos J, Nohynek D, Penn LZ: Lovastatin induced control of blast cell growth in an elderly patient with acute myeloblastic leukemia. Leuk Lymphoma 2001, 40(5-6):659-662.

30. Thibault A, Samid D, Tompkins AC, Figg WD, Cooper MR, Hohl RJ, Trepel J, Liang B, Patronas N, Venzon DJ, et al:: Phase I study of lovastatin, an inhibitor of the mevalonate pathway, in patients with cancer. Clin Cancer Res 1996, 2(3):483-491.

31. Pestell KE, Hobbs SM, Titley JC, Kelland LR, Walton Ml: Effect of p53 status on sensitivity to platinum complexes in a human ovarian cancer cell line. Mol Pharmacol 2000, 57(3):503-511.

32. Meinhold-Heerlein I, Ninci E, Ikenberg H, Brandstetter T, Ihling C, Schwenk I, Straub A, Schmitt B, Bettendorf H, Iggo R, et al:: Evaluation of methods to detect p53 mutations in ovarian cancer. Oncology 2001, 60(2):176-188

33. Donk NW van de, Kamphuis MM, Lokhorst HM, Bloem AC: The cholesterol lowering drug lovastatin induces cell death in myeloma plasma cells. Leukemia 2002, 16(7):1362-1371.

34. Holmberg M, Sandberg C, Nygren P, Larsson R: Effects of lovastatin on a human myeloma cell line: increased sensitivity of a multidrug-resistant subline that expresses the $170 \mathrm{kDa}$ P-glycoprotein. Anticancer Drugs 1994, 5(5):598-600.

35. Dimitroulakos J, Yeger H: HMG-CoA reductase mediates the biological effects of retinoic acid on human neuroblastoma cells: lovastatin specifically targets P-glycoprotein-expressing cells. Nat Med 1996, 2(3):326-333.

36. Maksumova L, Ohnishi K, Muratkhodjaev F, Zhang W, Pan L, Takeshita A, Ohno R: Increased sensitivity of multidrug-resistant myeloid leukemia cell lines to lovastatin. Leukemia 2000, 14(8):1444-1450.

37. Knox JJ, Siu LL, Chen E, Dimitroulakos J, Kamel-Reid S, Moore MJ, Chin S, Irish J, LaFramboise S, Oza AM: A Phase I trial of prolonged administration of lovastatin in patients with recurrent or metastatic squamous cell carcinoma of the head and neck or of the cervix. Eur J Cancer 2005, 41(4):523-530.

38. Spek E van der, Bloem AC, Donk NW van de, Bogers $L H$, Griend $R$ van der, Kramer MH, de Weerdt O, Wittebol S, Lokhorst HM: Dose-finding study of high-dose simvastatin combined with standard chemotherapy in patients with relapsed or refractory myeloma or lymphoma. Haematologica 2006, 91(4):542-545.

39. Spek E van der, Bloem AC, Sinnige HA, Lokhorst HM: High dose simvastatin does not reverse resistance to vincristine, adriamycin, and dexamethasone (VAD) in myeloma. Haematologica 2007, 92(12): $130-131$.

40. Elmore RG, loffe Y, Scoles DR, Karlan BY, Li AJ: Impact of statin therapy on survival in epithelial ovarian cancer. Gynecol Oncol 2008, 111(1):102-105.

41. Johnatty SE, Beesley J, Paul J, Fereday S, Spurdle AB, Webb PM, Byth K, Marsh S, McLeod H, Harnett PR, et al:: ABCB1 (MDR 1) polymorphisms and progression-free survival among women with ovarian cancer following paclitaxel/carboplatin chemotherapy. Clin Cancer Res 2008, 14(17):5594-5601.

42. Zhou SF: Structure, function and regulation of P-glycoprotein and its clinical relevance in drug disposition. Xenobiotica 2008, 38(78):802-832. 
43. Bogman K, Peyer AK, Torok M, Kusters E, Drewe J: HMG-CoA reductase inhibitors and P-glycoprotein modulation. Br J Pharmacol 2001, 132(6):1183-1192.

44. Wang E, Casciano CN, Clement RP, Johnson WW: HMG-CoA reductase inhibitors (statins) characterized as direct inhibitors of P-glycoprotein. Pharm Res 2001, 18(6):800-806.

45. Sakaeda T, Fujino H, Komoto C, Kakumoto M, Jin JS, Iwaki K, Nishiguchi K, Nakamura T, Okamura N, Okumura K: Effects of acid and lactone forms of eight HMG-CoA reductase inhibitors on CYP-mediated metabolism and MDR1-mediated transport. Pharm Res 2006, 23(3):506-512.

46. Chen C, Mireles RJ, Campbell SD, Lin J, Mills JB, Xu JJ, Smolarek TA: Differential interaction of 3-hydroxy-3-methylglutaryl-coa reductase inhibitors with ABCB1, ABCC2, and OATP1B1. Drug Metab Dispos 2005, 33(4):537-546

47. Rozados VR, Hinrichsen LI, Binda MM, Gervasoni SI, Matar P, Bonfil RD, Scharovsky OG: Lovastatin enhances the antitumoral and apoptotic activity of doxorubicin in murine tumor models. Oncol Rep 2008, 19(5):1205-1211.

48. Riad A, Bien S, Westermann D, Becher PM, Loya K, Landmesser U, Kroemer HK, Schultheiss HP, Tschope C: Pretreatment with statin attenuates the cardiotoxicity of Doxorubicin in mice. Cancer Res 2009, 69(2):695-699.

49. Damrot J, Nubel T, Epe B, Roos WP, Kaina B, Fritz G: Lovastatin protects human endothelial cells from the genotoxic and cytotoxic effects of the anticancer drugs doxorubicin and etoposide. Br J Pharmacol 2006 149(8):988-997

50. Neuvonen PJ, Niemi M, Backman JT: Drug interactions with lipidlowering drugs: mechanisms and clinical relevance. Clin Pharmacol Ther 2006, 80(6):565-581.

51. Kim WS, Kim MM, Choi HJ, Yoon SS, Lee MH, Park K, Park CH, Kang WK: Phase II study of high-dose lovastatin in patients with advanced gastric adenocarcinoma. Invest New Drugs 2001, 19(1):81-83.

52. Larner J, Jane J, Laws E, Packer R, Myers C, Shaffrey M: A phase I-II trial of lovastatin for anaplastic astrocytoma and glioblastoma multiforme. Am J Clin Oncol 1998, 21(6):579-583.

53. Holstein SA, Knapp HR, Clamon GH, Murry DJ, Hohl RJ: Pharmacodynamic effects of high dose lovastatin in subjects with advanced malignancies. Cancer Chemother Pharmacol 2006, 57(2):155-164.

54. Lersch C, Schmelz R, Erdmann J, Hollweck R, Schulte-Frohlinde E, Eckel F, Nader M, Schusdziarra V: Treatment of HCC with pravastatin, octreotide, or gemcitabine--a critical evaluation. Hepatogastroenterology 2004, 51(58):1099-1103.

55. Lopez-Aguilar E, Sepulveda-Vildosola AC, Rivera-Marquez H, CerecedoDiaz F, Valdez-Sanchez M, Villasis-Keever MA: Security and maximal tolerated doses of fluvastatin in pediatric cancer patients. Arch Med Res 1999, 30(2):128-131.

56. Garwood ER, Kumar AS, Baehner FL, Moore DH, Au A, Hylton N, Flowers Cl, Garber J, Lesnikoski BA, Hwang ES, et al:: Fluvastatin reduces proliferation and increases apoptosis in women with high grade breast cancer. Breast Cancer Res Treat 2009.

57. Lee J, Jung KH, Park YS, Ahn JB, Shin SJ, Im SA, Oh do Y, Shin DB, Kim TW, Lee $N$, et al:: Simvastatin plus irinotecan, 5-fluorouracil, and leucovorin (FOLFIRI) as first-line chemotherapy in metastatic colorectal patients: a multicenter phase II study. Cancer Chemother Pharmacol 2009 64(4):657-663.

\section{Pre-publication history}

The pre-publication history for this paper can be accessed here: http://www.biomedcentral.com/1471-2407/10/103/prepub

doi: $10.1186 / 1471-2407-10-103$

Cite this article as: Martirosyan et al., Lovastatin induces apoptosis of ovarian cancer cells and synergizes with doxorubicin: potential therapeutic relevance BMC Cancer 2010, 10:103

\section{Submit your next manuscript to BioMed Central} and take full advantage of:

- Convenient online submission

- Thorough peer review

- No space constraints or color figure charges

- Immediate publication on acceptance

- Inclusion in PubMed, CAS, Scopus and Google Scholar

- Research which is freely available for redistribution

Submit your manuscript at www.biomedcentral.com/submit
C Biomed Central 